\title{
Lateral preference for identical geometric forms: I. Normals
}

\author{
JOHN J. WINTERS, JR. AND IRMA R. GERJUOY \\ JOHNSTONE TRAINING AND RESEARCH CENTER, BORDENTOWN. NEW JERSEY
}

Ss made size discriminations between two identical and equal-sized geometric forms presented tachistoscopically. Under "larger" instructions the right side stimulus was chosen more often. Under "smaller" instructions and 30 sec. intertrial interval, the left side was chosen more often; with $10 \mathrm{sec}$. intertrial interval and "smaller" instructions perceptual and motor preferences canceled one another.

Adult Ss have been found to exhibit strong response preferences in a number of experimental tasks. For example, if the more frequently reinforced side in a binary-choice probability learning task is the right side, Ss tend to overmatch the probability of reinforcement, while if the more frequently reinforced side is the left, Ss tend to undermatch (Gerjuoy, Gerjuoy, \& Mathias, 1964; Miller, in press) . A right-side preference has also been found in binary-choice guessing-game tasks without reinforcement (Gerjuoy \& Winters, 1965; Iwahara, 1959). In all these studies the right-side preference was strong initially and decreased by varying degrees after the first trial.

In studies of perception a similar right-side preference has been demonstrated. Winters and Gerjuoy (1965), in a study of gamma movement, found that normal Ss perceived the right-hand stimulus as the larger significantly more often than the left when the side of presentation for the standard and comparison circles was counterbalanced. This unexpected result led to a further investigation of the effects of lateral preference on perceptual choice response. The same Ss, high school students, were given a second task to determine whether the tendency to perceive the right-hand of two geometric figures as the larger was restricted to tachistoscopic presentation, or whether it would occur under unlimited exposure time. Ss' self-paced task was to choose the larger of two equal-sized simple geometric figures presented on cards. These Ss exhibited a strong right-side preference. In both these tasks Ss maintained the preference throughout.

In the gamma movement study just cited, the exposure of the standard circle always preceded that of the comparison circle. The present experiment was designed to determine whether the preference for judging the right-side figure as the larger would occur under simultaneous tachistoscopic exposure of twoidentical circles or other geometric figures. An additional purpose was to determine whether a side preference was related to the handedness or eyedness of the $S$.

If the right-side preference were found, it would be important to separate a right-side motor preference from a right-side perceptual preference. Consequently, two sets of instructions were utilized: (a) instructions to press the button on the side of the larger figure, and (b) instructions to press the button on the side of the smaller figure. If the side preference reflects a preference for use of the right hand, then instructions should be irrelevant, and Ss should press the right-hand button more often, regardless of instructions. If, on the other hand, the side preference is perceptual, (i.e., a tendency to see the right-hand figure as larger), Ss under "larger" instructions should press the right-hand button more often than the left, while Ss under "smaller" instructions should press the left-hand button significantly more often than the right. If both preferences are present, then they should be additive under larger instructions and conflict under smaller instructions.

This study also investigated the variable of time between stimulus presentations. Iwahara (1959) has shown that response tendencies change with longer intertrial intervals.

\section{Method}

Subjects. The Ss were 96 student volunteers from Swarthmore College whose ages ranged from 18-22. Equal numbers of Ss were randomly assigned to each of four treatment-combinations, the combinations of "larger" or "smaller" instructions with $10 \mathrm{sec}$. or $30 \mathrm{sec}$. intertrial interval. One additional $\mathrm{S}$ was discarded for failure to respond on one trial.

Apparatus. The stimuli were presented in a modified Gerbrands tachistoscope that has been described elsewhere (Winters \& Gerjuoy, 1965). Two telegraph keys, with buttons coated with luminous paint and placed side by side $5-1 / 2$ in. apart below the eyepiece of the tachistoscope, were used as the response manipulanda. A pen recorder connected to the two telegraph keys and the tachistoscope recorded the onset and offset of the stimuli and the depression of each of the buttons.

Stimulus materials. The stimuli consisted of five identical pairs of geometric figures: triangles, circles, squares, semicircles, and diamonds. The contours of each pair of figures were drawn in black India ink on white $25 \mathrm{~cm} \times 27 \mathrm{~cm}$ cards. The centers of the figures, placed equidistant from the center of the card, were 7 $\mathrm{cm}$ apart; the areas of the figures were $12.5 \mathrm{sq} . \mathrm{cm}$.

Procedure. Ss were seated in front of the apparatus and dark adapted for $3 \mathrm{~min}$. before the instructions were read. In order to ensure that Ss were viewing the entire stimulus field, they were shown a large black square outline and instructed to adjust their heads until they could see all four sides. They were then told 
Table 1.

Mean Number of Judgments of the Right-Hand Stimulus as the Larger $(\mathbf{E}[\mathbf{x}]=\mathbf{5 . 0})$

Group

\begin{tabular}{|c|c|c|c|}
\hline & $10 \mathrm{sec}$. & $\frac{L}{5.8}$ & $\begin{array}{c}5 \\
5.5\end{array}$ \\
\hline 1978 & 30 sec. & 6.1 & 4.2 \\
\hline
\end{tabular}

to keep their heads in that position until the end of the experiment. Ss in the "larger" instruction group (Group L) were told that each time they heard a buzz (the ready signal) a light would flash on and they would see two black shapes that were almost the same size. They were instructed to look at them carefully and push the button on the side of the bigger shape. They were cautioned to push only one of the two response buttons. Ss in the "smaller" instruction group (Group S) were given the same instructions with the word "smaller" substituted for the word "bigger."

Each stimulus pair was exposed for $0.8 \mathrm{sec}$. The intertrial interval was $10 \mathrm{sec}$. for half the Ss in each instructional group and $30 \mathrm{sec}$, for the remaining Ss. The stimulus pairs were presented in the same order for all Ss. After all five cards were presented, they were inverted so that the left-hand stimulus became the righthand stimulus and vice versa. They were exposed a second time in the new position to control for any objective differences within stimulus pairs. Thus, each $S$ received 10 trials.

Following the experimental task, $S$ was given the hole-in-card test (Harris, 1958) to test his eyedness. $\mathrm{He}$ was also required to write his name to indicate his preferred hand.

\section{Results}

Group L exhibited a significant preference for judging the right-hand figure as larger on the first response $\left(X^{2}=5.33, p<.05\right)$. Sixty-seven percent of these Ss chose the right side as the larger. There was no significant side preference exhibited by Group $S$ on the first trial.

The mean numbers of judgments of the right-hand stimulus as the larger for the four treatment groups are presented in Table 1 . Over all 10 trials the rightside responses of each group were analyzed in a 2 by 2 analysis of variance. Both the main effect of Instructions $(F=9.77, p<.01)$ and the Instructions by Intertrial Interval interaction $(F=4.23, p<.05)$ were significant. Group L made significantly more right-side responses than Group S. This difference was greater under the 30 sec. than under the $10 \mathrm{sec}$. intertrial interval. Both the $10 \mathrm{sec}$. and $30 \mathrm{sec}$. subgroups of Group L made significantly more judgments of the right-hand stimulus as larger than would be expected by chance. The $30 \mathrm{sec}$. subgroup of Group $\mathrm{S}$ made significantly more judgments of the left-hand stimulus as smaller than would be expected by chance. The responses of the $10 \mathrm{sec}$. subgroup of Group S did not differ from chance.
The number of right and left responses did not differ significantly from the first half of the task to the second half. Since the positions of the stimuli were reversed for the two halves of the experimental task, this result ensures that there were no objective differences in size between the stimulus members of any pair.

Each stimulus pair was analyzed separately for side preference. For all Ss combined, the tendency to perceive the right side as the larger (or the left side as the smaller) approached significance for the triangles $\left(X^{2}=3.52, .10>p>.05\right)$ and reached significance for the circles $\left(X^{2}=15.19, p<.001\right)$. The triangle was perceived as larger on the right primarily because it was presented on the first trial. The percentages of right-side stimuli as larger for the five figures were: circles, $64.1 \%$; triangles, $56.8 \%$; squares, $54.7 \%$; semicircles, $51.6 \%$; and diamonds, $50.5 \%$.

The responses of the $\mathrm{Ss}$ were unrelated to their measured handedness or eyedness.

\section{Discussion}

The data from the present experiment support previous studies indicating that normal adult Ss exhibit a right-side preference. In this experimental situation Ss apparently perceived the right-side stimulus as the larger of the two regardless of instructions. It might be argued that under these experimental conditions two separate intra-subject tendencies are operating: a learned or experiential right-hand motor preference and purely perceptual process that makes one side appear larger. If such is the case, one might expect a larger proportion of people in our right-hand world to exhibit a right-hand motor preference than a left, independently of the percept of one side as larger than the other. If there is, in addition, a right-side perceptual enlargement, there should be an additive tendency when Ss are instructed to respond to the larger stimulus. On the other hand, when Ss are instructed to respond to the smaller figure, the experiential tendency to respond with the right hand should be subtractive. Since the data did not show a symmetry for the two instructional conditions (i.e.o there was a greater tendency to judge the right-side stimulus as larger under "large" instructions than to judge the left-side stimulus as smaller under "small" instructions), the data support the two-process hypothesis. It may be further hypothesized that these two separate processes may differ in relative strength with different experimental conditions. The results suggest that under a shorter intertrial interval the motor preference was predominant while under a longer intertrial interval the perceptual component took precedence.

The preference for the circle to be seen as larger on the right side under tachistoscopic presentation, in contrast to the other geometric forms, may be due to differences in subjective expansion rate of different geometric figures that are flashed on. According to Lindemann (1922) and Newman (1934) gamma move- 
ment is less marked with circles than with other simple geometric figures. If the other forms expanded more than the circles, the increased expansion of the rightside figure in these pairs would be less noticeable than with circles that do not expand as much. The differential ratio between the subjective sizes of the circles would, therefore, be larger than between any other pair of figures. Under unlimited exposure time there should be no difference between figures of various shapes, and any preference for seeing the right-side as the larger would be as likely with one figure as with another. No difference between geometric forms was found for urlimited exposure time in a previous study (Winters \& Gerjuoy, 1965).

In summary, the results of this study suggest that two processes, a preference to respond with the right hand and a tendency to see the right-hand figure of two equal-sized stimuli as the larger, were confounded. They can be separated by requiring $S$ to make a nonmotor response. It has been demonstrated previously that the motor preference decreases over trials, but it appears that the perceptual enlargement may be more persistent over trials.

\section{References}

Gerjuoy, 1. R., Gerjuoy, H., \& Mathias, R. Probability learning: Left-right variables and response latency. $J$. exp. Psychol., $1964,68,344-350$.

Gerjuoy, I. R., \& Winters, J. J., Jr. Binary-choice responses of retardates, normal children, and college students to similar or dissimilar stimuli. Amer. J. ment. Defic., 1965, 70, 474-477.

Harris, A. J. Harris tests of lateral dominance: Manual of directions for administration and interpretation. (3rd ed.) New York: Psychological Corporation, 1958.

Iwahara, S. Studies of spontaneous alternation in human subjects: III. A developmental study. Jap. psychol. Res., 1959, 1, 1-8.

Lindemann, E. Experimentelle Untersuchungen über das Entstehen und Vergehen von Gestalten. Psychol, Forsch., 1922, 2, 5-60.

Miller, M. E. Right-response preference in probability learning and reversal. J. exp. Psychol., in press.

Newman, E. B. Versuche über das Gamma-Phenomen. Psychol. Forsch., 1934, 19, 102-121.

Winters, J. J., Jr., \& Gerjuoy, I. R. Gamma movement: Field brightness, series, and side of the standard. Psychon. Sci., 1965, 2, 273-274.

\section{Note}

1. The authors wish to express their appreciation to the students at Swarthmore College who volunteered to participate in this experiment. We also wish to thank Peter L. Carlton, David L. Hoats, and Herman H. Spitz for their editorial comments.

(Received in the Editorial office February 11, 1966.) 